\title{
Obese Children Sustain Significantly More Both Bones Forearm Fractures When Compared to Non-Obese Children
}

\author{
Cavuoto Aldo ${ }^{1}$, Stettler Nicolas ${ }^{2}$, Zambelli Pierre-Yves ${ }^{1}$, Tercier Stephane ${ }^{1}$, Bregou Aline ${ }^{1}$ and Lutz Nicolas ${ }^{1}$ \\ ${ }^{1}$ Department of pediatric orthopedic surgery and traumatology, University Hospital of Lausanne, Switzerland \\ ${ }^{2}$ Division of Gastroenterology, Hepatology and Nutrition, Children's Hospital of Philadelphia, USA
}

"Corresponding author: Aldo Cavuoto, Department of Pediatric Orthopedic Surgery and Traumatology, University Hospital of Lausanne, 1003 Lausanne, Vaud, Switzerland, Tel: +41795594167; Fax: +41327254359; E-mail: Aldo.Cavuoto@Gmail.Com

Rec date: Jan 13, 2015, Acc date: Feb 16, 2015, Pub date: Feb 18, 2015

Copyright: $\odot 2015$ Cavuoto A, et al. This is an open-access article distributed under the terms of the Creative Commons Attribution License, which permits unrestricted use, distribution, and reproduction in any medium, provided the original author and source are credited.

\begin{abstract}
Objectives: Obesity in children is associated with an increased risk for fracture. The causes remain unclear and may be related to increased bone weakness during periods of intense growth or increased kinetics (when falling).

The hypothesis was that obese children sustain more severe fractures compared to non-obese children, and needed more treatment under general anesthesia (GA).

Methods: It was a prospective study in which date were collected during 6 months on obese and non-obese children presenting to the emergency room with an Upper extremity Long Bones Fractures (ULBF). The children's activity prior to trauma was assessed with a questionnaire. The mechanism of injury, the characteristics of the fracture defined using a validated pediatric classification and the treatment modalities were compared.
\end{abstract}

Results: The calculated prevalence of obesity in children with ULBF was $28 \% .46$ obese children aged 2 to 13 years and 119 non-obese children aged 2 to 16 years were included in the study. The risk for sustaining both bones forearm fractures was twice higher in obese children when compared to non-obese children $(p=0.012)$. Obese children required a higher number of manipulations under GA $(p=0.092)$.

Conclusions: The prevalence of obesity in children with ULBF was higher than in the general pediatric population. There was no statistical difference between both groups in the reported level of activity, in the kinetics and in the treatment modalities. Obese children had a significantly higher risk for a combined radius-ulna fracture. Further research is needed to evaluate the relationship between obesity, bone growth and trauma.

Keywords: Obesity; Children; Fracture; Trauma

\section{Introduction}

The causes for obese children to have a higher risk for fracture are a matter of debate. With the significant increase in the prevalence of obesity among children came specific issues such as early diabetes and hypertension. Trauma issues in obese children have become a matter of interest in the last 5 years. Obese children may be clumsier, overactive during shorter periods of time or more prone to fall. None of these possible causes of injures have been yet formally identified as risk factors specific to obese children.

Several studies have shown an increased risk for obese children to sustain a fracture when compared to non-obese children [1-4]. This risk is not only related to the activity of the child (play, fall, traffic accidents, etc...), but is also related to bone biomechanical properties and injury kinetics. Transient bone weakness (relative osteopenia) during the development of the child was linked to the increased risk for fracture [5]. Both hormonal changes and child's diet influence bone accrual and therefore affect bone biomechanical properties [6]. In obese children, it remains unclear whether the higher risk for fracture is related to decreased bone accrual or to significant injury kinetics. It was shown that higher BMI increases the kinetics when there is impact of an arm on the floor [1]. It was suggested that obesity induces poor balance with some transient developmental coordination disorder, which could increase the risk for fracture [7]. On the other hand, some studies suggested that obesity in children could have a protective effect, such as an increased bone mineral density $[8,9]$ or the hypothetical "cushioning effect" of fat when falling, for which no evidence has been established yet.

The hypothesis was that obese children with similar kinetics of injury sustain significantly more severe fractures than non-obese. This would mean that similar fractures would occur at lower kinetics if the children were obese.

Assessing the activity prior to trauma, the fracture's characteristics, as well as its treatment modalities would help us to better understand the relationship between fractures and obesity in children.

\section{Materials and Methods}

The study was performed in a university pediatric medical center over a period of 6 months. With the approval of the local ethics committee, each child between 2 and 16 years of age presenting to the emergencies for an upper extremity long bones fracture (ULBF) was approached for inclusion into the study. The data recorded included age, gender, height and weight, any history of previous fractures, grade 
of activity level, the kinetics of injury, the type of fracture and treatment modalities. Nurses measured anthropometric parameters in the emergency department at the time of injury or in the outpatient clinic at the first follow up (one week to 10 days after trauma). The Body Mass Index (BMI) was calculated and the children were classified between obese $(\mathrm{BMI}>=95$ percentile) and non-obese $(\mathrm{BMI}<95)$ using validated Swiss BMI percentiles for girls and boys aged 2 to 20 years [10] and were compared for each data recorded. The child was treated according to local standards of care and these treatment modalities were also recorded.

\begin{tabular}{|c|c|c|c|c|}
\hline Bone & Segment & Morphology & Severity & $\begin{array}{l}\text { Displacement } \\
\text { for epiphysis }\end{array}$ \\
\hline \multirow[t]{3}{*}{$\begin{array}{l}\text { Humerus }=1 \\
\text { Radius }=2 r \\
\text { Ulna }=2 u\end{array}$} & $\begin{array}{l}\text { Proximal/ } \\
\text { epiphysis or } \\
\text { metaphysis = } \\
1 \mathrm{E} \text { or } 1 \mathrm{M}\end{array}$ & \multirow[t]{3}{*}{1 to 9} & \multirow[t]{3}{*}{1 to 2} & \multirow[t]{3}{*}{ Type 1 to 4} \\
\hline & $\begin{array}{l}\text { Shaft/ } \\
\text { Diaphysis = } \\
2 \mathrm{D}\end{array}$ & & & \\
\hline & $\begin{array}{l}\text { Distal/ } \\
\text { epiphysis or } \\
\text { metaphysis = } \\
3 \mathrm{E} \text { or } 3 \mathrm{M}\end{array}$ & & & \\
\hline
\end{tabular}

Table 1: AO Pediatric Comprehensive Classification of long bone fractures (PCCF) [11].

Fracture classification was performed by review of the radiographs and radiological reports using the validated Pediatric Comprehensive Classification of long bone fractures (PCCF) of the "Arbeitsgemeinschaft für Osteosynthesefragen" (AO) (Table 1) [11]. For example a complete supracondylar fracture was codified as follows $13 \mathrm{M} / 3.1$. This classification allows detailed and reliable description of the fracture pattern and severity. A specifically designed database (AO COIAC $^{\otimes}$ ) was used to classify and list the fractures, as well as to record the mechanism of injury, treatment modalities, potential complications and outcome. A senior pediatric trauma surgeon reviewed all cases and doubtful classifications were further discussed and confirmed.

During the study period, a regular systematic review of the emergency data was performed to identify further cases of ULBF, which was not identified at the time of trauma. These children were approached for inclusion into the study by mail or at follow-up appointments.

The mechanism of injury was graded by assigning one of 3 different types of trauma kinetics to each child, as defined by the authors. Direct trauma was considered when an object hit the arm, traffic accident excluded. Slow motion trauma was considered when the injury happened while walking, running or falling from the child's height. High motion trauma was considered when the child were doing sport (every sport on wheels, ice-skating, etc...) or falling from more than 50 centimeters.

In order to assess the child's opportunities for fracture and exposure to trauma, the average daily activities during the week prior to trauma were graded using a validated pediatric Physical Activity Questionnaire (PAQ) aiming at children aged 4 to 16 years (PAQ-A and C) [12]. The PAQ defines 9 periods of activities performed throughout the day during the week. Each of these 9 items is graded 1 to 5 . The sum divided by the number of items gives a final grade between 1 (low physical activity) and 5 (high physical activity) [12]. The questionnaire was given or sent to each participating child with a return envelope as well as an explanatory letter.

Treatment modalities were classified by immobilization, external manipulation with immobilization or surgical treatment defined as any pinning, nailing or plating.

Children with cerebral palsy or bone diseases (such as bone cyst, osteogenesis imperfecta, etc...), as well as non-ambulatory children, were excluded from the study. Furthermore, re-fractures defined as occurring within 1 year of a previous fracture were also excluded. A review of our hospital medical and radiological records was performed to identify those cases.

For the statistical analysis, the Chi-Square test was applied using JMP 9.0.1. Statistical significance was considered when $\mathrm{p}<0.05$. A test for trend was performed for graduated variables such as injury kinetics and treatment modalities.

\section{Results}

\section{Subjects}

During the study period, 617 children were treated in the institution for one or more fractures, of which 232 were more than 2 years old and had a long bone fracture localized in the upper extremity. 2 patients declined the inclusion into the study. Exclusion criteria were met in 7 children, including 5 re-fractures and 2 chronic illnesses (1 child with generalized hypotonia of his lower extremities and 1 child with hypopituitarism). At the time of injury, the height measurement was missing in 58 patients, for which medical records review and analysis of weight with percentiles revealed overweight and suggested obesity in 4 (6.9\%).

The remaining 165 children were used as the basis of the study and divided in 46 obese and 119 non-obese children. The prevalence of obesity in this study group was $28 \%$.

The distribution by gender was the same in both groups (obese $40 \%$ female and $60 \%$ male versus non-obese $43 \%$ female and $57 \%$ male), similarly to what is found in the literature [13-15].

\section{Level of activity}

The PAQ activity questionnaire was given at the end of the emergency visit or during the first follow-up appointment. Due to a lack of consistency from our medical team in giving the questionnaire, only 104 of the 165 injured children received it. The overall response rate was $59.6 \%$, with 62 questionnaires completed and returned. The response rate was higher in the obese group $(67 \%, n=24)$ when compared to the non-obese group $(56 \%, \mathrm{n}=38)$. The mean calculated grade of activity level in the week prior to trauma was slightly higher for obese (2.64) than for non-obese (2.55) children. This was considered as a moderate level of activity in both groups (Table 2).

\section{Kinetics of injury}

Based on the history and mechanism of trauma, each child was assigned one of the three possible kinetics of injury. As showed in table 2 , obese children sustained more high motion trauma (57\%), when compared to non-obese (45\%), although this did not reach statistical significance $(\mathrm{OR}=1.56, \mathrm{CI} 95 \% 0.79-3.10, \mathrm{p}=0.20$ ). No statistically significant difference was found between both groups, even when 
Citation: Cavuoto A, Stettler N, Zambelli P, Tercier S, Bregou A, et al. (2015) Obese Children Sustain Significantly More Both Bones Forearm

analysis was adjusted for fracture location or number of fractured bones (Table 3).

\begin{tabular}{|c|c|c|c|}
\hline & Obese & Non-Obese & P-Value \\
\hline & $n=46$ & $n=119$ & \\
\hline Age mean (range) & 9.28 (2 to $13 y)$. & 9.31 (2 to $16 y$.) & 0.94 \\
\hline BMI mean (range) & 21.95 (17 to 29.8 ) & 16.89 (13 to 21.2$)$ & $<0.001^{*}$ \\
\hline PAQ GRADE mean (range) & 2.64 (2.11 to 4$)$ & 2.55 (1.6 to 4.3$)$ & 0.75 \\
\hline \multicolumn{4}{|l|}{ Kinetics of Trauma } \\
\hline Direct (\%) & $3(6 \%)$ & $15(13 \%)$ & 0.26 \\
\hline Slow motion (\%) & $17(37 \%)$ & $50(42 \%)$ & 0.55 \\
\hline High motion (\%) & $26(57 \%)$ & $54(45 \%)$ & 0.2 \\
\hline \multicolumn{4}{|l|}{ Fractures } \\
\hline Humerus (\%) & $7(15 \%)$ & $24(20 \%)$ & 0.47 \\
\hline Humerus and radius (\%) & $1(2 \%)$ & - & \\
\hline Radius (\%) & $17(37 \%)$ & $61(51 \%)$ & 0.1 \\
\hline Ulna (\%) & $1(2 \%)$ & $6(5 \%)$ & 0.41 \\
\hline Radius and ulna (\%) & $20(44 \%)$ & $28(24 \%)$ & $0.01^{*}$ \\
\hline \multicolumn{4}{|l|}{ Treatments } \\
\hline Immobilization (\%) & $32(70 \%)$ & $97(82 \%)$ & 0.1 \\
\hline Manipulation under general anesthesia (\%) & $11(24 \%)$ & $16(13 \%)$ & 0.1 \\
\hline Surgical pins (\%) & $3(6 \%)$ & $6(5 \%)$ & 0.71 \\
\hline Previous history of fracture (\%) & $11(24 \%)$ & $28(24 \%)$ & 0.95 \\
\hline
\end{tabular}

Table 2: Distribution of obese and non-obese children with regards to age, BMI, PAQ (Pediatric Physical Activity Questionnaire) grade, kinetics of injury, fracture location, treatment modalities and previous history of fracture. Results are given in ranges, percentages and $\mathrm{p}$ value $\left({ }^{\star}\right.$ when statistically significant).

\section{Fracture's characteristics}

As described in table 2, arm and forearm fractures were similarly distributed in the obese and non-obese groups (17\% and $83 \%$ versus $20 \%$ and $80 \%$, respectively). The distribution of fracture types is summarized in Fig. 1. In both groups, the most frequent forearm fractures were complete and distal buckle metaphyseal (17\% and 39\% versus $14 \%$ and $47 \%$, respectively). Distal forearm epiphyseal fractures were slightly more frequent in obese children (15\% versus $8 \%$ in nonobese children). This did not reach statistical significance.

When analyzing our data on both bones forearm fractures, we noted that obese children were twice more at risk, when compared to non-obese children ( $\mathrm{RR}=1.97, \mathrm{CI} 95 \% 1.16$ to $3.34, \mathrm{p}=0.012$ ) (Table 2).

\section{Treatment modalities}

The most common treatment modality was immobilization in both groups (70\% obese and $82 \%$ non-obese). Although not statistically significant, obese children required a higher number of manipulations under general anesthesia (GA) (24\% versus $13 \%$ for non-obese children. RR 1.27, CI 95\% 0.94-1.76, $\mathrm{p}=0.092$ ). There was no significant difference in the need for surgical treatment in both groups (6\% obese and $5 \%$ non-obese) (Table 2 ).

As summarized in Table 3, for distal humerus metaphysis fractures (classification code 13-M/3.1), obese children had an OR of 4.5 for Manipulation under GA or Surgical treatment, when compared to non-obese children (OR 4.5, CI95\% 0.31-65.3, $\mathrm{p}=0.25$ ).

\section{Previous bone injury}

A history of previous fracture to another bone or a history of a fracture more than one year old to the same bone was recorded in $24 \%$ of the children in both groups (Table 2). 
Citation: Cavuoto A, Stettler N, Zambelli P, Tercier S, Bregou A, et al. (2015) Obese Children Sustain Significantly More Both Bones Forearm Fractures When Compared to Non-Obese Children. Pediat Therapeut 5: 232. doi:10.4172/2161-0665.1000232

Page 4 of 6

\begin{tabular}{|c|c|c|c|c|c|}
\hline & Obese $n=46$ & Non-Obese $n=119$ & OR & $95 \% \mathrm{Cl}$ & P-Value \\
\hline \multicolumn{6}{|l|}{ Kinetics } \\
\hline Slow motion with ulna or radius fracture (\%) & $7(39 \%)$ & $31(46 \%)$ & 0.74 & $0.3-2.1$ & 0.58 \\
\hline High motion with both ulna and radius fracture (\%) & $13(65 \%)$ & $13(46 \%)$ & 2.14 & $0.7-7$ & 0.2 \\
\hline Slow motion with treatment under GA (\%) & $6(35 \%)$ & $11(22 \%)$ & 1.93 & $0.6-6.4$ & 0.28 \\
\hline High motion with treatment under GA (\%) & $8(31 \%)$ & $11(20 \%)$ & 1.74 & $0.6-5$ & 0.31 \\
\hline $\begin{array}{l}\text { High motion with a fracture of humerus } \\
\text { metaphysis distal } 13-\mathrm{M} / 3.1 \mathrm{I}-\mathrm{IV}(\%)\end{array}$ & $2(33 \%)$ & $7(70 \%)$ & 0.21 & $0.02-1.9$ & 0.15 \\
\hline $\begin{array}{l}\text { High motion with a fracture of radius and/or ulna } \\
\text { diaphysis } 12-\mathrm{D}(\%)\end{array}$ & $2(50 \%)$ & - & - & - & 0.1 \\
\hline $\begin{array}{l}\text { High motion with a fracture of radius and/or ulna } \\
\text { metaphysis distal } 23-\mathrm{M} / 3.1(\%)\end{array}$ & $5(63 \%)$ & $7(44 \%)$ & 2.14 & $0.4-12.2$ & 0.39 \\
\hline $\begin{array}{l}\text { High motion with a fracture of radius and/or ulna } \\
\text { epiphysis distal } 23-E(\%)\end{array}$ & $2(50 \%)$ & $5(50 \%)$ & 1 & $0.09-10.2$ & 1 \\
\hline \multicolumn{6}{|l|}{ Fractures types } \\
\hline \multicolumn{6}{|l|}{ Arm } \\
\hline Humerus proximal $11-\mathrm{M}$ and $11-\mathrm{E}(\%)$ & $1(2 \%)$ & $8(7 \%)$ & 0.31 & $0.03-2.5$ & 0.25 \\
\hline Humerus diaphysis 12-D (\%) & $1(2 \%)$ & - & - & - & 0.11 \\
\hline Humerus metaphysis distal 13-M/3.1 I-IV (\%) & $6(13 \%)$ & $10(8 \%)$ & 1.64 & $0.5-4.8$ & 0.37 \\
\hline Humerus epiphysis distal 13-E (\%) & - & $3(2 \%)$ & - & - & 0.28 \\
\hline \multicolumn{6}{|l|}{ Forearm } \\
\hline Radius and ulna proximal 21-M and 21-E (\%) & $1(2 \%)$ & $6(5 \%)$ & 0.42 & $0.05-3.6$ & 0.41 \\
\hline Radius and ulna diaphysis 22-D (\%) & $4(9 \%)$ & $6(5 \%)$ & 1.79 & $0.5-6.7$ & 0.38 \\
\hline Radius and ulna metaphysis distal 23-M/2.1 (\%) & $18(39 \%)$ & $56(47 \%)$ & 0.72 & $0.4-1.4$ & 0.36 \\
\hline Radius and ulna metaphysis distal 23-M/3.1 (\%) & $8(17 \%)$ & $17(14 \%)$ & 1.26 & $0.5-3.2$ & 0.62 \\
\hline Radius and ulna epiphysis distal 23-E (\%) & $7(15 \%)$ & $10(8 \%)$ & 1.96 & $0.7-5.5$ & 0.2 \\
\hline \multicolumn{6}{|l|}{ Treatment modalities } \\
\hline $\begin{array}{l}\text { Under GA with a fracture of humerus metaphysis } \\
\text { distal 13-M/3.1 I-IV (\%) }\end{array}$ & $2(33 \%)$ & $1(10 \%)$ & 4.5 & $0.3-65$ & 0.25 \\
\hline $\begin{array}{l}\text { Under GA with a fracture of radius and/or ulna } \\
\text { diaphysis } 12-\mathrm{D}(\%)\end{array}$ & $3(75 \%)$ & $3(50 \%)$ & 3 & $0.2-48$ & 0.43 \\
\hline $\begin{array}{l}\text { Under GA with a fracture of radius and/or ulna } \\
\text { metaphysis distal } 23-\mathrm{M} / 3.1(\%)\end{array}$ & $6(75 \%)$ & $7(41 \%)$ & 4.28 & $0.7-28$ & 0.11 \\
\hline $\begin{array}{l}\text { Under GA with a fracture of radius and/or ulna } \\
\text { epiphysis distal } 23-E(\%)\end{array}$ & $2(29 \%)$ & $5(56 \%)$ & 0.32 & $0.04-2.6$ & 0.28 \\
\hline Under GA with single bone of forearm (\%) & $3(17 \%)$ & $10(15 \%)$ & 1.14 & $0.3-4.7$ & 0.85 \\
\hline Under GA with both bones of forearm (\%) & $9(45 \%)$ & $8(29 \%)$ & 2.05 & $0.6-6.8$ & 0.24 \\
\hline
\end{tabular}

Table 3: Different types of fracture in both groups analyzed according to their kinetics and to their treatment modalities. 


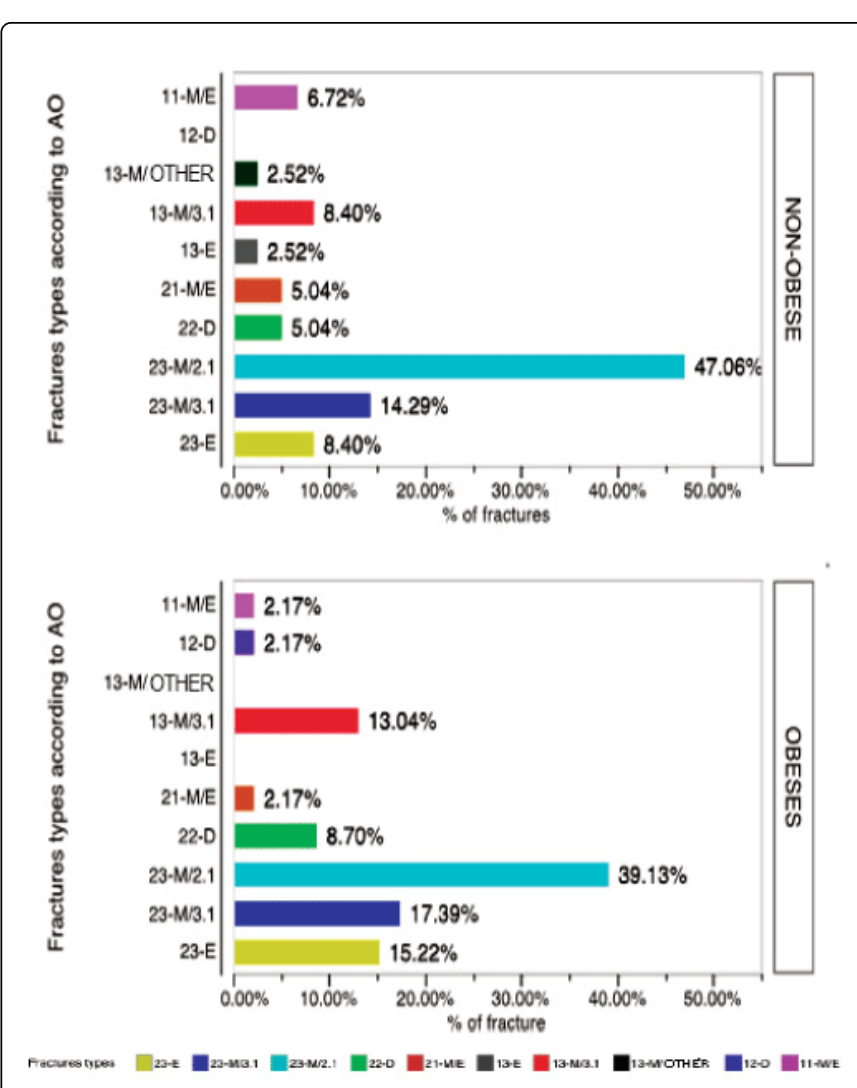

Figure 1: Distribution of fracture types in both groups according to AO classification.

For distal metaphyseal forearm fractures (classification code 23-M/ 3.1), obese children had an OR of 4.3 for Manipulation under GA or Surgical treatment when compared to non-obese children (OR 4.3, CI95\% 0.7-28, $\mathrm{p}=0.11$ ).

\section{Discussion}

Our study assessed ULBF treated in a single pediatric emergency department, which works as a primary care as well as a referral center. Three recent epidemiological studies in the Swiss pediatric population revealed a prevalence of obesity of around $7 \%[16,17]$.

We concluded that the high prevalence of obesity in this study (28\%) was not due to selection bias but a true representation of the Swiss pediatric population, supporting other published data revealing a higher risk for obese children to suffer from fractures [9]. Some studies suggested that poorer equilibrium, impaired mobility and greater force at low fall heights could contribute to this increased risk $[1,18]$.

Even when the 58 children with missing BMI were included in the study group, the estimated prevalence of obesity was $19,8 \%$. This was still way above the $7 \%$ prevalence of pediatric obesity in published Swiss surveys [19].

To our knowledge, no study has evaluated yet the relationship between activity level and the risk of fracture in obese children. Our aim was to see if obese children were significantly more active in the week prior to injury, therefore increasing their opportunities for fracture and exposure to trauma. We noted that the mean activity grade calculated with the PAQ was slightly higher in obese (2.64) than in non-obese (2.55) children. The small difference in the level of activity assessed by PAQ did not support the hypothesis that obese children had more opportunities for injury or were more exposed to trauma.

However in the literature, studies using accelerometers revealed overall lower levels of activity in obese children [20], although none has assessed specifically obese children with fractures.

Regarding the kinetics of injury, it was equally distributed in both groups, for high motion trauma being the most commonly recorded type.

Davidson et al have determined that obese children fall with much greater force than non-obese children. In addition they are at a relatively greater risk for fracture at low-fall heights [1]. Leonard et al proposed that the observed bone mineral increase in overweight children is not sufficient to overcome the significantly greater forces generated when an obese child falls on an outstretched arm [21]. Hormonal changes, lower dietary intake of calcium and inhibition of bone accrual secondary to a previous fracture have also been suggested as risk factors for fracture in obese children $[1,5,6,22]$.

Our results were not statistically significant and could not support the hypothesis that obese children have more fractures with slow motion kinetics of trauma, because of their higher BMI or increased energy on impact.

There was not statistically significant difference in the history of previous fracture between the two groups, which was in accordance with a recent cross-sectional Canadian study of children aged 12 to 17 years [23].

The distribution of fractures in both groups of children was not statistically significantly different, except for fractures of both bones of the forearm. Obese children were nearly twice more at risk of having a combined fracture of the radius and the ulna when compared to nonobese children (RR1.97, CI 95\% 1.16 to $3.34 \mathrm{p}=0.012$ ) (Table 2). The clinical relevance of it remains to be evaluated as some both bones forearm fractures tend to be more unstable, require more manipulation under GA or require more pining.

The overall higher number of manipulations under GA in obese children was noted to be more frequent with some types of fracture $(13 \mathrm{M} / 3.1$ and $23 \mathrm{M} / 3.1)$, as well as with both bones forearm fractures (Table 2 and 3). Although not statistically significant, this trend supported the hypothesis that more severe fractures requiring more invasive treatment are diagnosed in obese children, as it was the case for the lower extremity $[24,25]$.

Furthermore, general anesthesia for fracture manipulation in children is frequently required on an emergency basis. Adding obesity to emergency general anesthesia is adding risk factors such as hypertension, asthma and post-anesthesia apnea. These risk factors are well recognized by anesthesiologists.

\section{Limitations}

Although higher than initially expected, the total number of obese children with upper extremity fractures remained small. This could explain statistically non-significant results found during data analysis. 
The evaluation of the kinetics of injury was based on the history and categorized accordingly. Children skiing, biking or skating when getting hurt were considered as having sustained high motion trauma. In reality, they may have been moving at very low speed when the accident occurred and may have been misclassified. No precise information on the height and speed of fall was collected. There could be large variations of the energy on impact depending on the height and speed of a fall. In order to better assess the cause of injury in obese children, simple monitoring of the activity of the child is not enough. Movement's skills and physical fitness should be known and objectively assessed. Similarly, the muscle mass and the level of fatigue of the child at the time of injury should also be taken into account. These parameters could not be assessed in this retrospective study.

\section{Conclusion}

The high prevalence of obesity in injured children was confirmed in children with ULBF. This was much higher than the prevalence of obesity in the general pediatric population.

Assessing the level of activity and injury kinetics as well as the previous history of fracture, this study did not support one specific theory related to the increased prevalence of injuries in obese children. In order to better understand this relationship, several other factors must be considered such as bone accrural and neuro-motor coordination during growth. Reliable tools to analyze more precisely the kinetics of trauma in obese children are necessary to address the kinetics issue.

Obese children were nearly twice more at risk of having both bones forearm fractures when compared to non-obese children. They were more likely to require manipulation under GA.

Taking into account the burdens of pediatric obesity, further insight into the characteristics of bone quality and fractures in obese children is warranted.

\section{References}

1. Davidson PL, Goulding A, Chalmers DJ (2003) Biomechanical analysis of arm fracture in obese boys. J Paediatr Child Health 39: 657-664.

2. Manias K, McCabe D, Bishop N (2006) Fractures and recurrent fractures in children; varying effects of environmental factors as well as bone size and mass. Bone 39: 652-657.

3. Fornari ED, Suszter M, Roocroft J, Bastrom T, Edmonds EW, et al. (2013) Childhood Obesity as a Risk Factor for Lateral Condyle Fractures Over Supracondylar Humerus Fractures. Clinl Orthopaed Rel Res ${ }^{\oplus} .471$ : 1193-1198.

4. Seeley MA, Gagnier JJ, Srinivasan RC, Hensinger RN, VanderHave KL, et al. (2014) Obesity and Its Effects on Pediatric Supracondylar Humeral Fractures. The J Bone Joint Surg (American) 96: e18.

5. Ferrari SL, Chevalley T, Bonjour JP, Rizzoli R (2006) Childhood fractures are associated with decreased bone mass gain during puberty: an early marker of persistent bone fragility? J Bone Miner Res 21: 501-507.

6. Dimitri P, Bishop N, Walsh JS, Eastell R (2011) Obesity is a risk factor for fracture in children but is protective against fracture in adults: A paradox. Bone.
7. Zhu YC, Wu SK, Cairney J (2011) Obesity and motor coordination ability in Taiwanese children with and without developmental coordination disorder. Res Dev Disabil 32: 801-817.

8. Chan G, Chen CT (2009) Musculoskeletal effects of obesity. Curr Opin Pediatr 21: 65-70.

9. Taylor ED, Theim KR, Mirch MC, Ghorbani S, Tanofsky-Kraff M, et al. (2006) Orthopedic complications of overweight in children and adolescents. Pediatrics 117: 2167-2174.

10. Prader A, Largo RH, Molinari L, Issler C (1989) Physical growth of Swiss children from birth to 20 years of age. First Zurich longitudinal study of growth and development. Helv Paediatr Acta Suppl 52: 1-125.

11. Slongo TF, Audigé L (2007) Fracture and dislocation classification compendium for children: the AO pediatric comprehensive classification of long bone fractures (PCCF). J Orthop Trauma 21(10 Suppl): S135S160.

12. Kowalski KC, Crocker PRE, Donen RM, Honours B (2004) The physical activity questionnaire for older children (PAQ-C) and adolescents (PAQA) manual. College of Kinesiology, University of Saskatchewan.

13. Haricharan RN, Griffin RL, Barnhart DC, Harmon CM, McGwin G (2009) Injury patterns among obese children involved in motor vehicle collisions. J Pediatr Surg 44: 1218-1222.

14. Zaveri PP, Morris DM, Freishtat RJ, Brown K (2009) Overweight children: are they at increased risk for severe injury in motor vehicle collisions? Accid Anal Prev 41: 959-962.

15. Ryan LM, Teach SJ, Searcy K, Singer SA, Wood R, et al. (2010) Epidemiology of pediatric forearm fractures in Washington, DC. J Trauma 69(4 Suppl): S200-S205.

16. Olds T, Maher C, Zumin S, Péneau S, Lioret S, et al. (2011) Evidence that the prevalence of childhood overweight is plateauing: data from nine countries. Int J Pediatr Obes. 6: 342-360.

17. Lasserre AM, Chiolero A, Cachat F, Paccaud F, Bovet P (2007) Overweight in Swiss children and associations with children's and parent's characteristics. Obesity (Silver Spring) 15: 2912-2919.

18. Goulding A, Jones IE, Taylor RW, Piggot JM, Taylor D (2003) Dynamic and static tests of balance and postural sway in boys: effects of previous wrist bone fractures and high adiposity. Gait Posture 17: 136-141.

19. Aeberli I, Henschen I, Molinari L, Zimmermann M (2010) Stabilization of the prevalence of childhood obesity in Switzerland. Swiss Med Wkly 140: w13046.

20. Trost SG, Kerr LM, Ward DS, Pate RR (2001) Physical activity and determinants of physical activity in obese and non-obese children. Int J Obes Relat Metab Disord 25: 822-829.

21. Leonard MB, Shults J, Wilson BA, Tershakovec AM, Zemel BS (2004) Obesity during childhood and adolescence augments bone mass and bone dimensions. Am J Clin Nutr 80: 514-523.

22. Dimitri P, Wales JK, Bishop N (2010) Fat and bone in children: differential effects of obesity on bone size and mass according to fracture history. J Bone Miner Res 25: 527-536.

23. Doan Q, Koehoorn M, Kissoon N (2010) Body mass index and the risk of acute injury in adolescents. Paediatr Child Health 15: 351-356.

24. Spaine LA, Bollen SR (1996) "The bigger they come ...”: the relationship between body mass index and severity of ankle fractures. Injury 27 : 687-689.

25. Rana AR, Michalsky MP, Teich S, Groner JI, Caniano DA, et al. (2009) Childhood obesity: a risk factor for injuries observed at a level-1 trauma center. J Pediatr Surg 44: 1601-1605. 